\title{
POPULISMO NA AMÉRICA LATINA
}

\author{
POPULISM IN LATIN AMERICA
}

\author{
Luiz Alves Farias Filho ${ }^{1}$
}

RESUMO: O presente trabalho busca realizar análises sobre o conceito de populismo e como ele se desenvolveu na América Latina. Populismo é visto como um fenômeno político de definição ainda estudada por muitos autores devido as suas inúmeras formas de apresentação nas sociedades. A partir da década de 1940 o termo ganha corpo nos países periféricos, para explicar o surgimento de figuras carismáticas, com forte apelo popular e apoio a setores minoritários da sociedade. Foi feita observação de três casos específicos que ocorreram na Argentina e no México, que são os casos de maior destaque nas análises históricas. $O$ populismo ainda está longe de ser definido e caracterizado como um fenômeno homogêneo, devidos as vicissitudes doa países no qual se possibilitou a observância do mesmo.

Palavra-Chave: Populismo. América Latina. Peronismo. Cardenismo.

ABSTRACT: This paper seeks to conduct analysis on the concept of populism and how it developed in Latin America. Populism is seen as a political phenomenon whose definition is still being studied by many authors due to its numerous forms of presentation in societies. Starting in the I940s the term gains body in peripheral countries to explain the emergence of charismatic figures with strong popular appeal and support for minority sectors of society. Observations were made of three specific cases that occurred in Argentina and Mexico, which are the most prominent cases in historical analyses. Populism is still far from being defined and characterized as a homogeneous phenomenon, due to the vicissitudes of the countries in which it was possible to observe it.

Keyword: Populism. Latin America. Peronism. Cardenism.

\section{INTRODUÇÃO}

Ainda há muitas divergências em torno da definição do termo populismo, muitos autores não conseguem descreve-lo devido a complexidade dos contextos que o envolve. Muito antes do termo ser amplamente utilizado no início do século XX, já se havia usado

'Graduando em História pela Universidade Federal do Amazonas (UFAM). E-mail: laf.filho@gmail.com. 
outras vezes na história. Por toda América Latina podemos perceber diversos movimentos populistas, no Uruguai, No Brasil, na Guatemala, na Argentina etc.

O populismo ganha força na América Latina com os processos de industrialização e com o aparecimento de uma forte camada industrial urbana. O texto dividido em 7 seções busca elucidar as discordâncias e características do populismo na América Latina, através da conceitualização e análise de três principais movimentos: Cardenismo, Peronismo.

Do ponto de vista metodológico, buscou-se realizar a análise através de fontes de livros e artigos científicos.

\section{POPULISMO}

Populismo é visto como um fenômeno político de definição ainda estudada por muitos autores devido as suas inúmeras formas de apresentação nas sociedades. Os estudos que se pautaram a partir da apresentação do conceito buscavam compreender as características comuns entre o fenômeno, porém cada caso do populismo corresponde a uma característica diferente, que age de acordo com as estruturas e relações políticas e sociais construídas.

Ferreras (20II) faz um apanhado dos primeiros movimentos considerados populistas no mundo e seus principais analistas, como Gino Germani, que analisa o movimento soba a ótica da teoria das modernizações entendendo o populismo como o resultado de um momento de transição da sociedade tradicional para a moderna, sendo esta etapa extremamente necessária para os países da América Latina e os países periféricos em geral. Germani partia da identificação do movimento como uma variante do fascismo.

O fato é que o termo populismo não foi inventado pelos países periféricos, desde o século XVII já se falava em populismo nos Estados Unidos através de um movimento ocorrido, quando ocorreu forte oposição á concentração de terras nas mãos da elite agrária e ferroviária especuladores e donos de estradas. Os produtores agrários do Sul colocavam a culpa nestes, que ficavam com o lucro e resolveram se organizar politicamente para reverter a situação, culminando no People’s Party, denominando-se populistas os participantes. $\mathrm{O}$ partido não durou muito tempo. 
A partir da década de 1940 o termo já utilizado tanto por pesquisadores quanto por pessoas leigas, ocupando o sentindo bem literal da palavra, expressando um sentido de "popular”. Com a chegada da década de 1950 e 1960, no entanto, o termo assume outro caráter, através da intensificação dos seus estudos, passando assim, a assumir uma posição mais pejorativa.

Segundo Gomes (200I), populismo pode ser definido como uma politica de massas, vinculada aos trabalhadores, que não adquiriram consciência de classe e não estão organizados e participando da política. Essas massas são interpretadas como originarias do proletariado, mas se diferenciando dele pela inconsciência das relações de exploração, sendo somente a superação dessa condição que o levaria a libertação do populismo e a consciência de classe. Conforme o autor:

[...] o populismo está igualmente associado a uma certa conformação da classe dirigente, que perdeu sua representatividade e poder de exemplaridade, deixando de criar os valores e os estilos de vida orientadores de toda a sociedade. Em crise e sem condições de dirigir com segurança o Estado, a classe dominante precisa conquistar o apoio político das massas emergentes. Finalmente satisfeitas estas duas condições mais amplas, é preciso um terceiro elemento para completar o ciclo: o surgimento do líder populista, do homem carregado de carisma, capaz de mobilizar as massas e empolgar o poder (GOMES, 200I)

Ferreiras (20II) faz uma periodização do populismo dividindo-o em três momentos: Precoce, conhecido como radicalismo das classes médias que operou nas primeiras décadas do século XX. O populismo clássico, que vigorou nas décadas de 1930 a 1950, marcado pela mobilização das classes urbanas, pelo Estado de bem-estar social e o crescimento industrial. Tardio, operado pela década posterior a 1950, visando um retorno as experiencias anteriores, sem constituir processos originais. E por último, o neopopulismo, que surgiu a partir da década de 1980, fase de consolidação da democracia, onde governos propuseram a criticar o populismo por suas políticas sociais e trabalhistas.

Uma outra autora que se propõe a identificar as características do populismo é Galito (2017), através do populismo de esquerda e o populismo de direita. O primeiro assumiria um caráter ideológico progressista, através de programas políticos com uma maior intervenção do Estado, sem monopólios privados e com mais liberdade, com reivindicações socioeconômicas e a ditadura do proletariado. 
Sobre o populismo de direita a autora complementa que, sua ideologia é conservadora, com menor interferência do Estado, contra os monopólios públicos, oferecendo mais segurança para as massas, com maior responsabilidade social, acabar com os pobres, apoiando nacionalismos e identidades culturais e religiosas (GALITO, 2017).

O que nos importa que fique claro é o fato de o populismo não haver uma definição certeira para os modelos onde ele ocorreu. Devemos entendê-lo dentro das vicissitudes de cada lugar, pensando em um movimento de caráter múltiplo que se transformou ao longo das décadas e das mudanças que ocorreram no cenário mundial e local.

\section{POPULISMO LATINO-AMERICANO}

O populismo tem sido um fenômeno político que transformou as estruturas sociais e as relações entre Estado e sociedade na América Latina. Muitos estudiosos caracterizam o populismo como uma passagem da sociedade tradicional para a moderna, estando relacionado com as sociedades de massas, constituídas através dos processos de industrialização doa países da América Latina. Desde a Primeira e Segunda Guerra Mundial e a crise de 1929, a geopolítica mundial foi transformada impactando nos países Latino Americanos.

Apesar de muitos governos populistas coincidirem as mesmas épocas, as características que cada um traz, diferem entre si, não há nenhum consenso ou forma especifica para se tratar governos populistas. É neste momento de intensa industrialização tardia que as relações entre Estado e classe trabalhadora tomam novas formas.

Nas novas relações entre o trabalhador, os instrumentos de produção e o produto da força de trabalho, os componentes mágicos ou animalistas submerge sob as exigências impostas pelo ritmo e a escala da produção[...] sob vários aspectos, pois, o populismo é também um processo (político e sociocultural a um tempo) com o qual se dá a plena formação das relações de classes nas nações da América Latina (IANNI, i99i, p.io).

Somado ao avanço da industrialização latino-americana, autores descrevem o fenômeno como uma resposta ao contexto neoliberal que o mundo vivia, de reafirmação das politicas neoliberais com a inserção de economias tardiamente industrializadas na dinâmica mundial, com a necessidade de reafirmação social, politica e econômica. Conforme Ferreras (200I), a década de 1930 marcada pela crise de 1929, revigorou uma mudança nos governos 
que tentaram restaurar as sociedades aristocráticas do século XIX, retomando o liberalismo e o conservadorismo, que lhes permitiu chegar a grande produção de matéria-prima e a concentração de poder.

Ainda segundo o autor, estes mesmos, tiveram que lidar com a mudança social irreversível na sociedade, compreender que a economia havia mudado de formato após a crise, e tiveram que restabelecer novas funções de controle e administração do Estado.

Para começarmos nossa análise do populismo na América Latina, devemos considerar dois aspectos inerentes as análises. A comparação entre os movimentos populistas ocorridos deve levar em conta o caráter histórico que os países latinos possuem, por isso devemos deixar de lado as considerações que homogeneízam esses países. Devemos considerar as diferenças culturais, sociais, econômicas, religiosas, políticas etc. O desenvolvimento do continente americano não foi comum a todos, pois desde o processo de colonização dos territórios, a maioria deles passou pelo processo exploratório, se traduzindo mais a frente como um processo de industrialização e desenvolvimento tardio.

É nesse mesmo ponto que as histórias de cruzam e se complementam, pois todos estão inseridos dentro da lógica do capitalismo mundial e contribuíam de forma grandiosa para a formação dos grandes impérios nacionais através da exploração de seus territórios. Desde o processo de expansão do capitalismo industrial inglês até a queda da bolsa de valores e 1929, nações latino americanas estão ativamente ligadas aos eventos.

O populismo latino americano tem sido analisado a luzes de fatores como, o processo de industrialização, modernização e democratização por muitos autores que consideram estes fatores complementares, que explicam o desenvolvimento social e político dos países. Nesse processo encontram-se as massas recém chegadas do campo, sem a compreensão dos valores socioculturais da cidade, formando o que Ianni (1991) chama de "massas marginais".

Essas massas se encontram em processo de integração no meio urbano, que não possui instituições políticas capazes de conduzir esta integração, daí surgem o que muitos autores definem como o sucesso do populismo, que é definido por autores como Gino Germani como movimento político e social característico de sociedades em transição para a industrialização. 
Portanto, analisar o surgimento desse movimento politico na América Latina é considerar os lados da moeda que a caracteriza, o desenvolvimento desigual que cabe a cada país e o desenvolvimento histórico e social que caracteriza esses países até hoje. Nesta seção descreveremos dois casos mais conhecidos do populismo na América latina; o Peronismo na Argentina e o Cardenismo, no México.

\section{I Argentina: Peronismo}

O termo populismo vai ser amplamente difundido na Argentina a partir de Juan Domingo Perón. Juan fazia parte do Exercito argentino até o golpe de 1943, quando esteve no exercito presenciou alguns conflitos e tentou fazer sua carreira dentro da instituição. A argentina vivia sob as consequências de um golpe em 1930, com um grupo antidemocrático e radical no poder, aliado a isto estava a condição social e política no país.

O golpe de 1943 foi uma saída para esta situação, articulada pelos setores do exército argentino. Todavia, haviam discordância sobre o que se faria após o golpe, e em um piscar de olhos, Péron foi nomeado diretor do Departamento Nacional do Trabalho, afim de manter a paz social com o setor trabalhista, dentro disso Perón viu a necessidade do auxilio do Estado para o setor manter a luta por seus direitos. Posteriormente Péron chegou ao Ministério do Exercito criando a Secretaria de Trabalho e Previsão e logo chegou a vice presidente. Em 1945 foi deposto pelos companheiros de exército e preso.

Os trabalhadores argentinos viram esta prisão com péssimos olhos, entendiam que sem Péron suas reivindicações não seriam atendidas pelo Estado, a partir disso foi criado um movimento pela liberdade de Péron que alcançou índices jamais esperados, em i7 de outubro, um movimento na Praça de maio pedia pela liberdade de Péron, obtendo êxito logo em seguida. Em fevereiro de 1946, vence as eleições baseado no discurso anti-imperialista, com oposição dos Estados Unidos.

Quando chega ao poder, o novo presidente tentou reformular a legislação social e política através de uma maior atuação sindical, estatizou empresas de transportes, petróleo, investiu em indústria de base e produção de energia elétrica e a reformulação da Constituição. Péron incentivou o consumo das classes populares beneficiando os setores industriais, contudo, perdeu apoio quando o crescimento econômico se inverteu. Os trabalhadores agrários não estiveram entre as políticas de Péron, já o exército esteve no 
centro do governo com papel de dirigir as empresas do Estado, porém dentro da corporação haviam muitas conspirações contra a aliança de Perón com a classe trabalhadora (FERRERAS, 20II).

Com a criação do Partido Democrata Cristão em 1954, Péron retira os privilégios da Igreja por achar a atitude ofensiva. A partir de 1952 tudo começa a mudar, quando finalmente Péron é surpreendido por um golpe de Estado, planejado pelo exército. De acordo com Ferreras (2011):

\begin{abstract}
A partir de então Péron, tentou controlar o movimento operário e fazer uma política econômica menos agressiva e mais consensual [...] os trabalhadores perderam centralidade no projeto, os empresários questionaram a falta de compromisso do governo no controle dos trabalhadores que favorecesse um crescimento da produtividade, a Igreja se afastou e os militares se sentiram cada vez mais isolados de uma sociedade que se radicalizava contra o peronismo [...] em 1955 ocorreram atentados e, finalmente, um golpe liderado pelo Exército, uma de suas principais bases, derrubou Péron e seu governo. (FERREIRAS, 20II).
\end{abstract}

\title{
3.2 Mexico: Cardenismo
}

Cárdenas governou o México de 1936 a 1940. Participou de conflitos militares da revolução e logo após iniciou carreira politica entrando para o Partido Nacional Revolucionário (PNR). Com a crise de 1929, Cárdenas governou com base na superação da mesma, através da mobilização das massas e do afastamento das politicas de seus predecessores.

Entre as demandas defendidas por ele estavam os camponeses que pediam uma reforma agrária e os trabalhadores urbanos, que estavam relegados desde o governo anterior. Conforme Ferreras (2011):

[...] ele encerrou os conflitos existentes com a Igreja. Ainda que o Estado controlasse a educação e a organização da sociedade civil, a Igreja retomou suas atividades educacionais e confessionais sem conflitos, porém numa situação de subalternidade (Ferreras, 20II).

Cárdenas também promoveu uma aliança com os trabalhadores, agora eram os trabalhadores industriais, funcionários do Estado e das empresas privadas estrangeiras, principalmente do petróleo, que que procuravam ajuda do Estado. Sua política também foi voltada para os camponeses, que continuou com os planos que Calles executou, ampliando as propriedades comunitárias, ele também nacionalizou as estradas de ferro que aliada a 
reforma agraria foi motivo para criar um desconforto entre alguns países que controlavam estas fazendas.

O os trabalhadores petroleiros reivindicavam melhor condições de trabalho e salários, em protesto paralisaram a produção, o governo interviu a favor dos trabalhadores estatizando as industrias fazendo com que os países boicotassem o México, Cárdenas aproveitou a ocasião e unificou setores que não eram favoráveis a seu governo.

O conflito do petróleo teve consequências econômicas elo fechamento dos mercados internacionais, o que levou ao encerramento da etapa reformista. Desde 1938 o governo foi muito menos ativo e propenso a entrar em conflitos que não tinha mais como controlar ou dar curso (FERRERAS, 2011).

O papel do Estado na mobilização, propositalmente ou não, foi decisivo porque deu centralidade às demandas de diferentes setores e as fortaleceu. Finalmente essa ligação com o Estado permitiu o fortalecimento das organizações populares cujas reivindicações foram encampadas e adquiriram o status de políticas de Estado (FERRERAS, 2oII).

Assim Cárdenas foi perdendo impulso no avanço das eleições através de um combinado de motivos, a mudança da situação internacional, a necessidade de estabilidade nas relações internacionais. Cárdenas assumiu uma política nacionalista, a favor dos oprimidos pelas pressões estrangeiras. No fim do seu mandato que já estava desgastado, viuse emergir um candidato de visões bem opostas a Cárdenas, que desacelerou as mudanças continuando a governar, todavia com um viés mais conservados, promovendo a continuidade das reformas.

\subsection{CONSIDERAÇÕES FINAIS}

Buscou-se analisar o fenômeno populista sobre a ótica de autores que pesquisam o tema a alguns anos em busca da definição para o movimento. Através da compreensão de que a América Latina é extensa e seus países possuem desenvolvimento heterogêneo apesar de compartilharem praticamente ao mesmo tempo, processos de industrialização e surgimento das massas trabalhadoras, estes processos possuem cicatrizes que não se correlacionam.

Com os exemplos ocorridos na Argentina e no México aqui exemplificados, pode-se perceber a heterogeneidade com o que o populismo acontece, sem haver uma receita mágica para se tornar um chefe populista. Não há como se tomar como forma especifica ou exemplar 
nenhum dos acontecimentos, pois os dois fenômenos caracterizam épocas distintas, formações de classes distintas. O que podemos chegar a conclusão, é de que os movimentos exemplificados mudaram as perspectivas da época e construíram um legado histórico para além do que vivenciaram.

\section{REFERÊNCIAS}

BATISTELLA, Alessandro. Um conceito em reflexão: o "populismo" e a sua operacionalidade. Revista Latino-Americana de História, vol. I, 2012.

BAQUERO, Marcelo, Populismo e neopopulismo na América Latina: o seu legado nos partidos e na cultura. Soc. E Cult., Goiânia, vol. 13, nº 2, p. 189-192, 2010.

DUSSEL, Enrique. Cinco tesis sobre el “populismo”. UAM-Iztapalapa, México, 2007. FERRERAS, Norberto. A sociedade de massas: os populismos. In: História das Américas: novas perspectivas. Orgs: Cecília Azevedo, Ronald Raminelli. Rio de janeiro, FGV, 201 .

GAlitO, Maria Sousa. Populismo - Conceptualização do Fenómeno. Working Peper CEsA, 2017. p.32.

GOMES, Angela de Castro. "O populismo e as ciências sociais no Brasil: notas sobre a trajetória de um conceito”. In: FERREIRA, Jorge (Org.). O populismo e sua história: debate e crítica. Rio de Janeiro: Civilização Brasileira, 2001, p. 17-58.

GOMES, Angela de Castro. Reflexões em torno de populismo e trabalhismo. Varia História, Belo Horizonte, nº 28, dezembro 2002, p. 55-68.

GOMES, Angela de Castro. A invenção do trabalhismo. 3. ed. Rio de Janeiro: FGV, 2005. [I $\mathrm{I}$ - edição de 1988].

IANNI, Octavio. A formação do Estado Populista na América Latina. Rio de janeiro, CIVILIZAÇÃO BRASILEIRA S.A, I991. p. I62. 